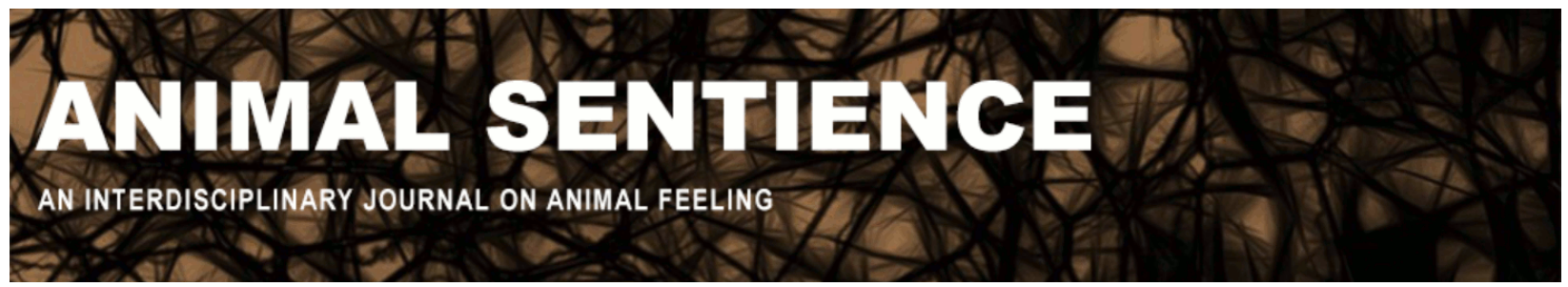

Merck, Melinda V. (2016) Veterinary medical associations need to educate veterinarians for mandatory reporting of suspected animal abuse. Animal Sentience 6(5)

DOI: $10.51291 / 2377-7478.1097$

Date of submission: 2016-02-24

Date of acceptance: 2016-02-27

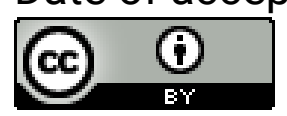

This article has appeared in the journal Animal

Sentience, a peer-reviewed journal on animal

cognition and feeling. It has been made open access,

free for all, by WellBeing International and deposited

in the WBI Studies Repository. For more information,

please contact

wbisr-info@wellbeingintl.org.

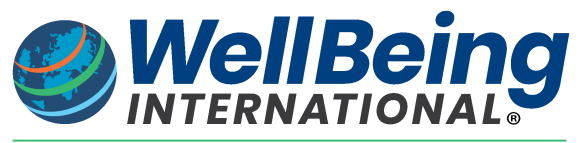

SOLUTIONS FOR PEOPLE, ANIMALS AND ENVIRONMENT 


\title{
Veterinary medical associations need to educate veterinarians for mandatory reporting of suspected animal abuse \\ Commentary on Lachance on Breaking Silence
}

\author{
Melinda D. Merck \\ Veterinary Forensics Consulting, LLC \\ Austin, Texas, USA
}

\begin{abstract}
When animals are suffering, we have a duty to take action. With appropriate incentive and educational support mandatory veterinary reporting can be a great legal avenue to help ensure their safety and welfare.
\end{abstract}

\begin{abstract}
Melinda Merck catdvm@drmerck.com is a forensic veterinarian consulting on cases involving animals, assisting investigators of animal cruelty with crime scene investigation. She is on the Board of Directors for North American Veterinary Community, founding member of the

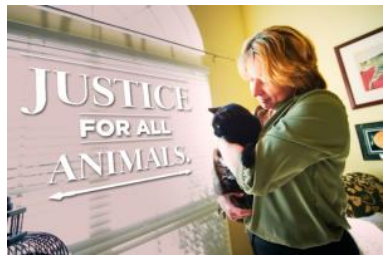
Board of Directors for the International Veterinary Forensic Sciences Association, and editor of Veterinary Forensics: Animal Cruelty Investigations (Wiley). http://www.veterinaryforensics.com
\end{abstract}

The veterinarian's duty to report suspected cruelty is an important issue. Lachance's (2016) target article addresses many of the issues that the veterinary and legal community face. The conflicts discussed can be reasonably resolved with certain actions, but educational support and changing the mindset of the veterinary community are also required.

It should be stressed that the reporting of abuse is for suspected abuse, the purpose of which is to initiate an investigation. The proven link of cruelty to other types of crimes is the foundation to support this action. Veterinarians in practice, regardless of the nature of the client relationship, cannot determine what is truly happening in the animal's home environment and must consider that other animals and people may be at risk. There may be a criminal history involving animals or people. In addition, the veterinarian cannot judge culpability. That is for the legal investigation to determine - if a crime occurred and who is responsible for the crime.

Most of the cases veterinarians will encounter in practice will be related either to domestic violence (Signal 2016) or to neglect. The domestic-violence-related cases often involve acute and/or prior physical injury. The neglect cases may present more challenges for the veterinarian. They may range from client compliance failure to hoarding. These can be less clear regarding when and whether to report. This is where the veterinarian should consult with the local investigator for advice. Veterinarians need to understand that they cannot enforce compliance; only the legal authorities can take action, which often results in proper intervention and 
monitoring. When an animal is suffering, we have a duty to take action that will ensure its safety and welfare.

There are several legal avenues that can support the veterinarian's duty to report. It is imperative that the veterinarian have legal protection from civil and criminal liability when reporting suspected abuse. It should be noted that when there is liability protection, it also implies that the veterinarian is expected to report. In Florida, the animal cruelty statute includes further protection for actions taken by the veterinarian in suspected abuse cases:

State of Florida Statute 282.12(4): A veterinarian licensed to practice in the state shall be held harmless from either criminal or civil liability for any decisions made or services rendered under the provisions of this section. Such a veterinarian is, therefore, under this subsection, immune from a lawsuit for his or her part in an investigation of cruelty to animals.

Mandatory reporting can be a great legal avenue; however, it must have the appropriate incentive and educational support. The veterinarians must receive training on how to recognize, document and respond to suspected animal cruelty (Fawcett 2016). This education should be provided by the national and provincial/state veterinary medical associations. We have to provide tools to the veterinary community and help create a different, proactive mindset that involves looking for ways to help the animal. The discussion of client confidentiality raises legitimate issues. There should be exceptions in every veterinary practice act or laws that support or allow the veterinarian to report suspected abuse.

Lachance's target article is a call to action for the veterinary and legal community to resolve all of these issues and place priority on the protection and welfare of the animals we serve.

\section{References}

Fawcett, A. (2016). Veterinarians need support to break the silence. Animal Sentience 2016.069.

Lachance, M. (2016). Breaking the silence: The veterinarian's duty to report. Animal Sentience 2016.006: 1-16.

Signal, T. (2016). When the client is not the abuser, but one of the abused. Animal Sentience 2016.076 . 